\title{
Geo-portal as a planning instrument: supporting decision making and fostering market potential of Energy efficiency in buildings
}

Research Article

\author{
Branka Cuca ${ }^{1,2 *}$, Raffaella Brumana ${ }^{1}$, Daniela Oreni ${ }^{1}$, Giuliana lannaccone ${ }^{1}$, Marta Maria Sesana ${ }^{1}$ \\ 1 Politecnico di Milano, Department of Architecture, Built environment and Construction Engineering (A.B.C.), \\ Via Ponzio 31, 20133 Milan, Italy \\ 2 Cyprus University of Technology, Department of Civil Engineering and Geomatics, \\ 2-8 Saripolou Str. 3036 Limassol, Cyprus
}

Received 21 January 2014; accepted 15 March 2014

\begin{abstract}
Steady technological progress has led to a noticeable advancement in disciplines associated with Earth observation. This has enabled information transition regarding changing scenarios, both natural and urban, to occur in (almost) real time. In particular, the need for integration on a local scale with the wider territorial framework has occurred in analysis and monitoring of built environments over the last few decades. The progress of Geographic Information (Gl) science has provided significant advancements when it comes to spatial analysis, while the almost free availability of the internet has ensured a fast and constant exchange of geo-information, even for everyday users' requirements. Due to its descriptive and semantic nature, geo-spatial information is capable of providing a complete overview of a certain phenomenon and of predicting the implications within the natural, social and economic context. However, in order to integrate geospatial data into decision making processes, it is necessary to provide a specific context, which is well supported by verified data. This paper investigates the potentials of geo-portals as planning instruments developed to share multi-temporal/multi-scale spatial data, responding to specific end-users' demands in the case of Energy efficiency in Buildings (EeB) across European countries. The case study regards the GeoCluster geo-portal and mapping tool (Project GE2O, FP7), built upon a GeoClustering methodology for mapping of indicators relevant for energy efficiency technologies in the construction sector.
\end{abstract}

Keywords: SDI $\cdot$ Web geospatial services $\cdot$ open-source geo-portal $•$ geo-clusters $\bullet$ energy efficiency in buildings

(c) Versita sp. z o.o.

\section{Nomenclature}

$\mathrm{EE}=$ Energy Efficiency

$\mathrm{EEB}=$ Energy Efficiency in Buildings

*E-mail: branka.cuca@polimi.it, branka.cuca@cut.ac.cy (Corresponding author)
GIS = Geographical information Systems

OGC = Open GIS Consortium

SDI = Spatial Data Infrastructure

WFS $=$ Web Feature Service

WMS = Web Map Service

WPS $=$ Web Processing Services 


\section{Introduction}

The Geographic Information System (GIS) represents the first coordinated approach for handling geospatial data and performing spatial analysis functions. The development of the internet and the shift towards using digital technologies over the last decades has led to quicker and more intuitive uses of spatial data - the Digital Earth. However, these two approaches differ substantially not only in the functionalities offered, but also in the approach and applications. While GIS concentrates more on spatial analysis of data and complex queries, Digital Earth bases its applications on visualisation, using an omni-comprehensive catalogue of the earth itself. As underlined by [1], applications of Digital Earth are not just limited versions of GIS, but they refer to a different and perhaps more important phenomena, given the extent of the geo-web community. This paper discusses web geo-portals as a complementary option that takes into account the main GIS function and at the same time provides several different visualisations of Earth's surface. Due to its descriptive and semantic nature, geo-spatial information is capable of providing a complete overview of a certain phenomenon, as well as foreseeing implications of this occurrence to its natural, social and economic framework. However, in order to ensure uptake into a decision making processes, Geographic Information (GI) need specific context. This paper studies the potentials of Spatial Data Infrastructures (SDI) and Geo-portals functions in a community-based society, using GeoCluster geo-portal and mapping tools for Energy efficiency in Buildings as a case study.

The recently adopted European Energy Efficiency Directive has established a common framework, by which the promotion of energy efficiency in buildings across Europe can be measured. Furthermore, this compulsory set of procedures lays down rules designed to overcome barriers in the energy market that hinder efficiency in the supply and use of energy, fostering the establishment of indicative national energy efficiency targets for the year 2020. In addition, the European Initiative on Smart Cities fosters the dissemination of the most efficient models and strategies to progress towards a low carbon future, focusing on measures on buildings, local energy networks and transport. When it comes to existing buildings, the initiative expects novel strategies for the refurbishment of at least $50 \%$ of the public buildings in the EU, as well as proposals for the original solutions in terms of technologies, innovative financing schemes, and refurbishment techniques. In this context, the GE2O mapping tool and knowledge repository, developed as products of the "Geo-clustering to deploy the potential of Energy efficient Buildings across
EU" FP7 EU project, were conceived to examine several technologies of major potential for the new refurbishing market, with focus on Thermal Insulation (TI) and Solar Cooling (SC). The tool is encompassed within a geoportal such that, together with a location, it can provide a geospatial connotation of certain parameters that are very often geo-dependent such as climate, construction typologies, energy prices, etc. This paper outlines a brief state-of-the-art use of geo-portals and the approach used for data collection (Section 2), the efforts involved in setting up such a platform in a comprehensive manner across Europe regarding Energy efficiency (section 3), and the challenges of metadata homogenization, limitations and many potentials for the tool (section 4). Maps of the tool are illustrated and commented upon in order to provide a full overview of the research done and the possible implications in terms of geo-clusters, which could set the scene for a high-potential exploitation of the market. In conclusion, this paper outlines the further necessity of implementation of such a Spatial Data Infrastructures (SDI) with data on national, regional and municipality levels in order to provide a more realistic picture of the market opportunities for local parties such as public authorities, practitioners, industries and SMEs.

\section{Materials and methods}

The term 'portal' indicates an access or entrance point [2] that translated in GI and SDI can define geo-portals as websites where geographical content is discovered [3]. In the era of Web 2.0, Gl no longer defines data born with intrinsic geo-descriptive coordinates, instead it is gradually becoming a synonym of any kind of geo-referenced information, taken into consideration for professional use or used in everyday life activities and business. Greater access to data and their better standardization was necessary for most public bodies in the 1980s [4], which eventually lead to the definition of SDI by the US National Research Council as "technology, policies, standards, human resources, and related activities necessary to acquire, process, distribute, use, maintain, and preserve spatial data throughout all levels of government, the private and nonprofit sectors and academia" [5]. Furthermore, there are two main reasons why spatial framework is essential in almost all GIS operations [6] and thus within webGIS:

(1) SDI provides both spatial context and spatial structure: possibility to connect with the real-world situation and to correct possible distortions;

(2) Most of geo-data collected by the institutions within national boundaries: data are usually collected for spe- 
cific purposes; there must be a "spatial key" able to register different data sets.

In recent years, Geo-portals have been defined as catalogue gateways that enable linkages between a wide collection of information such as data sets, services, tools and tutorials [7]. Similarly to geo-politics, when speaking of geo-portals both technical aspects of the discipline and policy issues that drive these instruments should be considered: they are impetus foreseen to mainly influence information sharing in the future. The development of the web has created a big boom when it comes to information access and sharing, with the same impact affecting geospatial information. More specifically, Web 2.0 is based on three main pillars [8]: (1) user generated content, (2) the interoperability of information and (3) inclusion of the social context of the user. For these reasons, geo-portals can be seen as "catalysts" between SDIs and the geospatial Web 2.0, acting as open systems that support the discovery, exchange, advertisement and delivery of geospatial information, as requested by the European INSPIRE Directive. This legal framework, conducted by the European Joint Research Centre (JRC), recommends developing spatial datasets and services as well as related metadata according to existing international standards and user requirements. The final product is an INSPIRE Geo-portal that contains geospatial information within a system of relevant themes across Europe. Other interesting actions on the global scale include on-going activities such as the Geospatial One-Stop (GOS) in the US [9], the Australian SDI [10], and the Indian SDI [11]. Within this framework, in recent years, several European regions have advanced their SDI approach to a process-oriented approach that foresees major user involvement [12]. The content of these kinds of SDls aim to tackle tasks related to specific user communities, such as cartographic heritage for landscape analysis [13], water bodies and other important topics. With regard to Energy efficiency in buildings, there are no specific cases of in which these kind of geo-portals are used at an EU level; although some interesting research results have been seen on data structuring (projects such as TABULA, BUILD UP, and others) and on the importance of geodatabases for building energy efficiency [14].

\subsection{Data collection and structure}

For the purpose of this research, both technological aspects and political-economic issues regarding energy efficiency were examined. In order to fully explore the capabilities of the envisaged Mapping tool, the two significant technologies, Thermal Insulation (TI) and Solar Cooling (SC) for Energy efficiency in Buildings were chosen. These two technologies have been selected in order to represent the two different data families to be correlated and the two potentially different geographical markets; Mediterranean Arch and Benelux. Additional reasons for a thorough comparison include the following:

- Technological Distinction: TI regards the building envelope, SC regards the energy systems;

- Geographical Distinction: TI is mostly favourable for northern countries, SC for southern countries;

- Technology Readiness Level: TI is very mature, SC is just emerging;

- Installation Complexity: TI is "ready-to-install", SC is linked to solar collector technologies;

- Design complexity: TI is "easy-to-design", SC requires specific background skills.

In order to set up data collection and methodology structure, firstly the different information required were separated into several main categories, as illustrated in Table 1:

Table 1. Terminology, as defined for the purposes of the research conducted within the GE2O project.

\begin{tabular}{ll}
\hline Technology & $\begin{array}{l}\text { Technology is defined by a single set of } \\
\text { performance indicators, product/system } \\
\text { characteristics, geo-descriptors, and de- } \\
\text { scriptors. Technology consists of differ- } \\
\text { ent products or systems. }\end{array}$ \\
\hline Parameter & $\begin{array}{l}\text { Factor, a system characteristics strictly } \\
\text { related to the technology }\end{array}$ \\
\hline Performance Indicator & $\begin{array}{l}\text { Factor related to the technology and } \\
\text { elaborated from a few parameters }\end{array}$ \\
\hline Geo-indicator & $\begin{array}{l}\text { Technology indicator depending on geo- } \\
\text { graphic location }\end{array}$ \\
\hline Geo-descriptor & $\begin{array}{l}\text { Context indicator with a geographic lo- } \\
\text { cation, geo-referenced to an area spa- } \\
\text { tially located or to single point coordi- } \\
\text { nates i.e. NOT dependent on a single } \\
\text { technology }\end{array}$ \\
\hline
\end{tabular}

These categories were then classified into a 3D correlation matrix, defined by $X Y Z$, where the variables describe the interactions, such that:

- X stands for energy efficiency technologies;

- $Y$ stands for the parameters and performance indicators: factors relating strictly to a specific technology; 


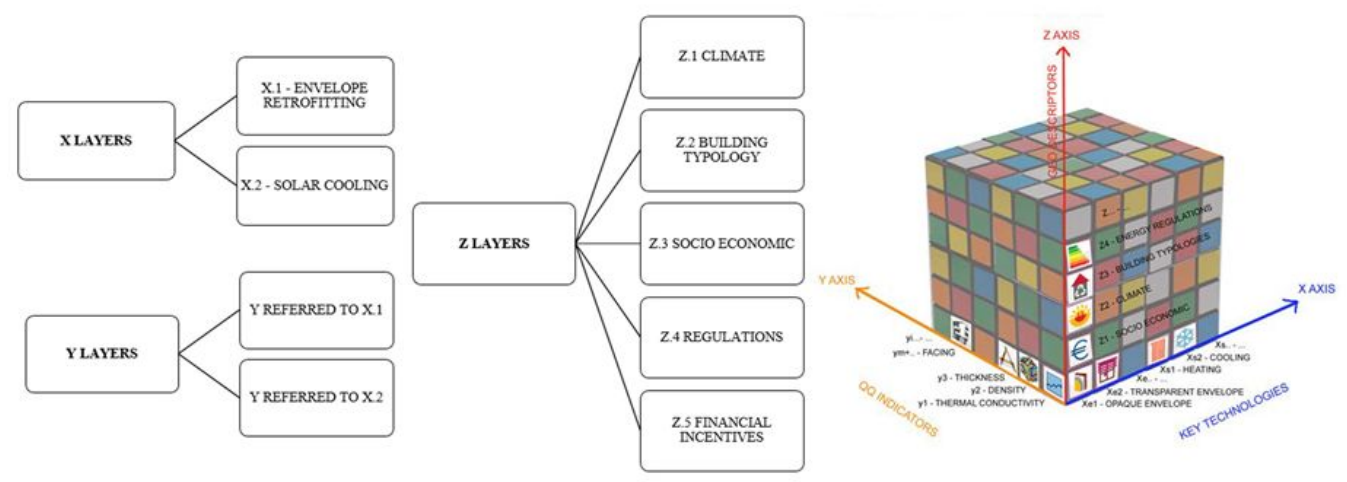

Figure 1. X-technologies, Y-indicators and Z-geo-descriptors (left); 3D correlation matrix (right).

- Z stands for geo-indicators and geo-descriptors: factor relating to a specific geographic location in which technology should be applied.

Data were collected for most of the European countries, using publicly available statistics data (catalogues of Eurostat and national statistics bodies) and information from previous national and European projects. The flexibility of a 3D model made it possible to place each key technology on the "XY plane" so that every technology can be identified and described by its "real" characteristics. However, a certain number of these parameters, such as thermo-hygrometric properties, costs, range of application, depend on another set of data that has a strong geographical and context relevance (climate conditions, socio-economics data, building typologies). Moreover, considering the specific aim of the geo-clustering approach, i.e. to identify the potential for application of energy efficient technologies, it has been observed that other non-technological data such as financial incentives, regulations, cultural aspects (to name a few) play a significant role in the application of a technology. All these geo-referenced data are virtually placed on the Z-axis and identified as geo-descriptors i.e. context indicators that do not depend on a single technology. In this way, the 3D matrix has made the correlation structure more dynamic (Fig. 1).

\subsection{GeoClustering correlation methodology}

The methodology adopted when dealing with heterogeneous information on a geographical level regards clustering and geo-clustering of qualitative and quantitative information on Energy efficiency in buildings ( $E e B)$ across European countries. In order to understand the correlation between the three axis $(X, Y, Z)$, we have to distinguish between two types of correlation: 1) $X$ to $Y$ correlation, and 2) XY to $Z$ correlation. However, both approaches are based on "Clustering Analysis" that defines different statistical procedures and relevant computational algorithms capable of dataset classification. This process has been carried out by gathering (clustering) initially unknown numerical or un-numerical values (cluster points).

Every technology, $X$, has its own list of specific intrinsic indicators, $Y$. This makes the correlation between $X$ and $Y$ occur between each technology and its indicators. In particular, the $Y$ - axis features two categories of parameters: (1) descriptive indicators related only to the specific embodiment of a single key technology $X$ (e.g. thermal conductivity of a material in the case of thermal insulation technology X1 and (2) performance indicators that depend on the application of the respective technology in specific environmental conditions, defined by the $\mathrm{Z}$ layer (keeping the example of thermal insulation $\mathrm{X} 1$, performance indicators are e.g. the average energy loss per square metre, depending on the $\mathrm{Z}$ parameters Heating/Cooling Degree Days). This correlation can be defined by the "methods for numeric objects". On the other side, Z geo-descriptors include all the external characteristics and conditions (social, economic, climatic, legislative and so on) that influence each key technology. For the purpose of this research, the focus was on Envelope Retrofitting and Solar Cooling. Z layers are related to their geographic location considering Nomenclature of Territorial Units for Statistics of Eurostat administrative unit level (NUTS3) for example cases; the Benelux and Mediterranean arc. In conclusion, every technology can be related to (1) its $\mathrm{Y}$ indicators and to (2) all relevant $Z$ layers (either directly or indirectly through $Y$ indicators). Applying this method on the above mentioned case studies, it was deduced that the correlation between the $Y$ and $Z$ variables can be clearly identified. Hence, the approach was applied to both technologies, identifying the connection that exists between indicators (e.g. Performance In- 
dicator) and external condition (e.g. Climate conditions). However, as discussed, many geo-descriptors ( $Z$ axis) cannot be described by a numeric value but by qualitative data. In this case, the "method for non-numeric objects" is applied. Since these variables are not represented by a number, some ad hoc "dissimilarity coefficients" have been introduced, which are able to quantify qualitative differences between non-numerical objects and to reveal similarities or differences between the two datasets examined. More details of this methodology can be found in [15]. Once defined, these descriptors are attributed to every single administrative unit of the two examined example cases at the NUTS3 level i.e. they become Geodescriptors (Z).

\section{Results: Geo-portal for energy efficiency in buildings}

The correlations between $X, Y$ and $Z$ were conducted on a European level, considering as many countries and their specific features as possible. Once the correlations and respective algorithms were defined, the visualization of the results through the mapping tool was obtained by an automated process.

In the future, as the database increases, and using these first cross-correlation results, an automatic approach to analyse and quantify the level of cross-correlation could be developed; a statistical approach could be used to analyse the number and frequency of recursive correlations.

This approach of creating Geo-clusters could have further applications in identifying market potentials for company investments, as well as raising awareness of decision making when it comes to the Energy Efficiency (EE), the refurbishment of existing buildings and to support related professional activities. All geographic and geo-referenced data, their metadata, users and tools are interactively connected in order to use spatial data in an efficient and flexible way, generating an Energy Efficiency SDI (EESDI), with the GE2O Knowledge Repository i.e. an example of Energy Efficiency Geographic EU platform.

\subsection{Geo-portal system architecture}

The GE2O application relies on a multi-tiered clientserver system (Fig. 2). Core components are all located on the server side. At the very inner tier (tier 2) we find a standard postgreSQL server, with geographic capabilities (postGIS). This database stores vector features and metadata, as well as Content Management System (CMS) specific data (in a separate database). The mid- dle tier (tier 1) is made up of two different web application servers: a standard web server that supports $\mathrm{Hy}$ pertext Preprocessor (PHP) and the map viewer engine (based on PHP). The GIS server providing Web Map Services (WMS) and Web Feature Services (WFS) to the map viewer is Geoserver that runs as a web application. GeoWebCache, also part of the tier 1, is Java web application used to cache map tiles coming from a variety of source such as Open Geospatial Consortium (OGC) WMS. It implements various service interfaces (such as WMS-C, Web Map Tile Service, Tile Map Service, Google Maps KML, Virtual Earth) in order to accelerate and optimize map image delivery. As far as the client-side (tier 0 ) is regarded, the only application involved is a standard web browser which allows the end user to navigate into the portal and the map viewer with no need for additional software. The map viewer includes the entire OpenLayers bundle (with support for proprietary imagery such as Google Maps) and ExtJS (for page layout). GeoExt is a library that combines the web mapping library Openlayers with ExtJS. It provides a suite of customizable widgets and data handling support that makes it easy to build applications for viewing, editing and styling geospatial information, as well as printing controls from a PDF serving platform, such as page layout, resolution, and legends.

Using an adapted set of classes and functions from OpenLayers, the map viewer provides:

- seamless browsing between geo-referenced maps of $\mathrm{X}, \mathrm{Y}$ and $\mathrm{Z}$ layers;

- a set of controls for zooming, panning, cursor positioning, real-time layer opacity changing and layer re-ordering;

- a complex set of customizable filtering by the end users;

- integration with third-parties, OGC-compliant external WMS resources;

- custom choice of the background layer, selecting bewteen an empty base or proprietary imagery (e.g. Google Satellite).

\subsection{Geo-portal outputs: first and second level maps}

The geo-portal Web Service Architecture has foreseen to provide answers in terms of WMS and WFS, following the requests of the final user. An approach based on information harmonization has been considered using large scale data on EU country levels together with small-scale information on levels of province or single city, in order 

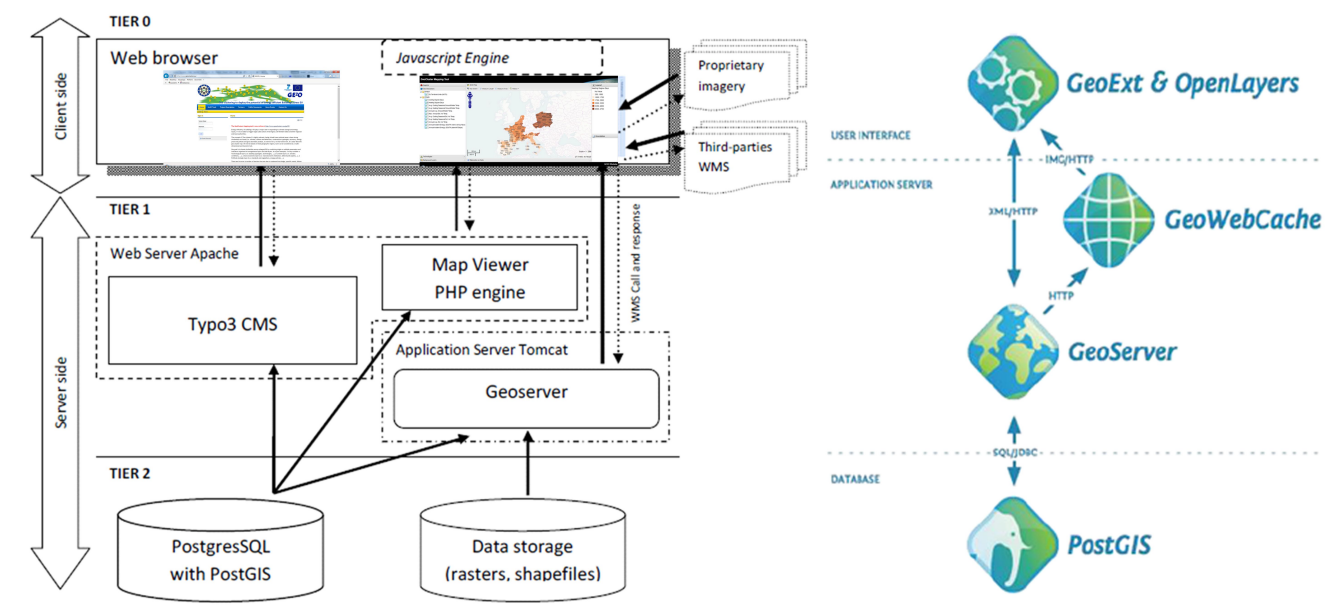

Figure 2. System Architecture of the GE2O Web Geo Portal: Common three tier Architecture (left) and an illustration of Open Source software and libraries employed (right).

to provide new scenarios for retrieving geospatial knowledge of the build environment. The methodology proposed addresses the exchange, sharing, access and use of interoperable spatial data, as stated by the EU Directive INSPIRE. In a practical sense, every layer described as a Geo-descriptor has its geographical location within the GeoCluster Mapping Tool, i.e. all Geo-descriptors are geo-referenced. A common geographic reference level, the NUTS3, used for small regions of specific diagnoses, was chosen. The correlation results show "value chains" that allow end users to visualise the output of the process on a technological map (Fig. 3). This approach gives access to all of the data and the possible correlations, whilst also guaranteeing an iterative process.

The maps generated by the GeoCluster Mapping Tool can be classified into 2 different levels: (1) the first level map i.e. thematic map of a single $X, Y$ or $Z$ which represents the values of a single layer according to the specific defined ranges; (2) the second level map i.e. correlations maps showing results of the correlation bewteen two or more indicators. Fig. 4 provides a graphic example of a first level map showing Heating Degree Days (Z.1.1), a sub-layer of the geo-descriptor Climate (Z.1).

\subsection{Example of Second level maps: Market potential for Thermal Insulation Technologies}

Thermal Insulation technologies were described considering 22 different examples structured in 5 families: Aerogels, Foam boards, Mineral Wool, Natural materials and Vacuum Panels (VP). The Fig. 5 illustrates the Market potential of the thermal insulation technology Sheep wool (Natural material), applied to envelope retrofitting in resi- dential buildings across EU, considering 5 thresholds. The colour range detects a very high potential (red) to a very low potential (light green).

The optimal thickness of the material, considering the climate conditions of a specific NUTS3 region, is displayed on the map. In addition, it is possible to customise the $U$-value of the material (overall heat transfer co-efficient) and consequently observe the changes on the map of Market penetration for a specific technology considered. In the same manner, it is possible to query the tool for all 22 technologies. A high number of variation and filters (including customisation of thickness of insulation material, pre-defined U-value and others), as well asstraight forward organization and display of data make the tool highly practical for end-users.

\section{Discussion}

During the data collection and methodology development, several barriers and limitations have been encountered, due to scattered knowledge, specific needs, failure modes and bottlenecks, as well as the weakness and threats experienced by running clusters dealing with energy efficiency in the built environment across Europe. The main limitations encountered refer to data quality, precision and scale; however, as this commonly occurs in GIS applications, the Geo-descriptors and all their sub-layers were assigned attributes of single geographic unit (polygon, points, lines). All attributes were referenced to the NUTS3 polygonal level, thus it is possible to represent the map resulting from the correlation of the climate attributes to their corresponding NUTS3 boundaries. Us- 


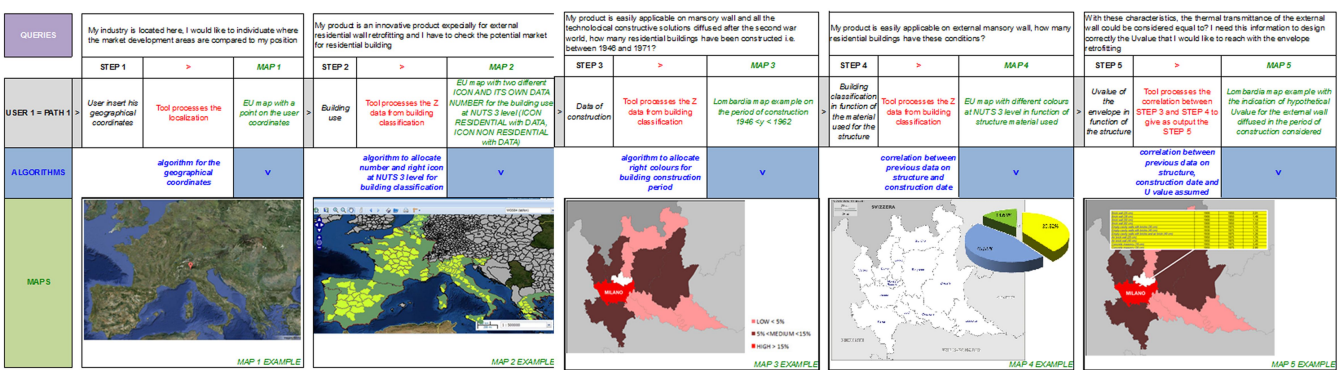

Figure 3. Value chain for a specific query (from left): majority of residential/non-residential stock at NUTS3 level; Lombardy Region (LR) residential construction over the period 1946-1960 (low-medium-high); LR - pie chart on the type of construction material used; LR indication of hypothetical U-value of external walls (period of construction).

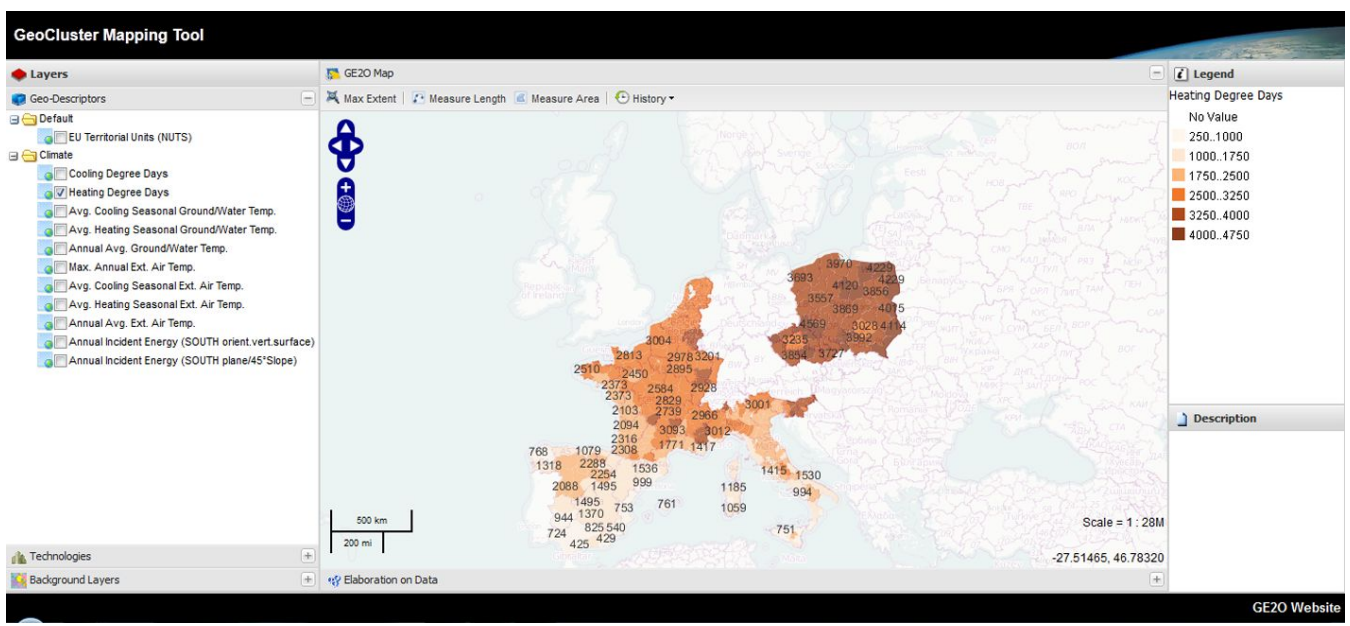

Figure 4. GE2O map of layer Z.1.1 Heating Degree Days. Screen shot of the GE2O Mapping Tool - GE2O Website.

ing this system it is possible for the end-user to view, understand, query, interpret, and visualize data in many ways that reveal relationships, patterns, and trends in the form of maps, reports and charts. Geo-spatial information is of crucial importance as it enables the scientific community and professionals to understand what the impact of anthropic influence on efficiency issues is. A better comprehension of territory and the built environment can lead to a more sustainable way of urban planning and improving territorial government facilities with citizen acknowledgement and participation. Strong support from the technological point of view is needed, both in terms of visualisation media or virtual environments as well as communication tools [16]. Also, significant Z layers, such as "Building Typologies", should be studied in more detail, applying advanced surveying and modelling technologies on existing building stock $[17,18]$ and buildings of historic importance [19]. The progressive implementation of various spatial data sources and with remote sensing data will be needed in to feature to improve Web Processing
Services (WPS) and support adaptive context-aware processing by the users. For example, thermal sensors can be very useful in identifying temperature anomalies in urban structures where the heat is lost in significant values [20]. Thermal infrared (TIR) remote sensing images can provide valuable environmental observation information and if combined with an airborne and or satellite platform, uses can also include: (i) land cover classification; (ii) urban heat island analysis; (iii) residential heat loss/waste heat mapping; and (iv) roof moisture surveys [21, 22] as well as others. Another very practical example of using the remote sensing technologies for mapping of cities is the European Urban Atlas initiative [23], which is part of the EO/Copernicus Land monitoring services. These high resolution maps obtained from satellite imagery in combination with the street network allow for a wide range of additional analyses such as proximity to green spaces, train stations, geometric shape of single districts, distance from energy resources, accurate pictures of urban sprawl in the fringe of urban zones and many more. Integrating 


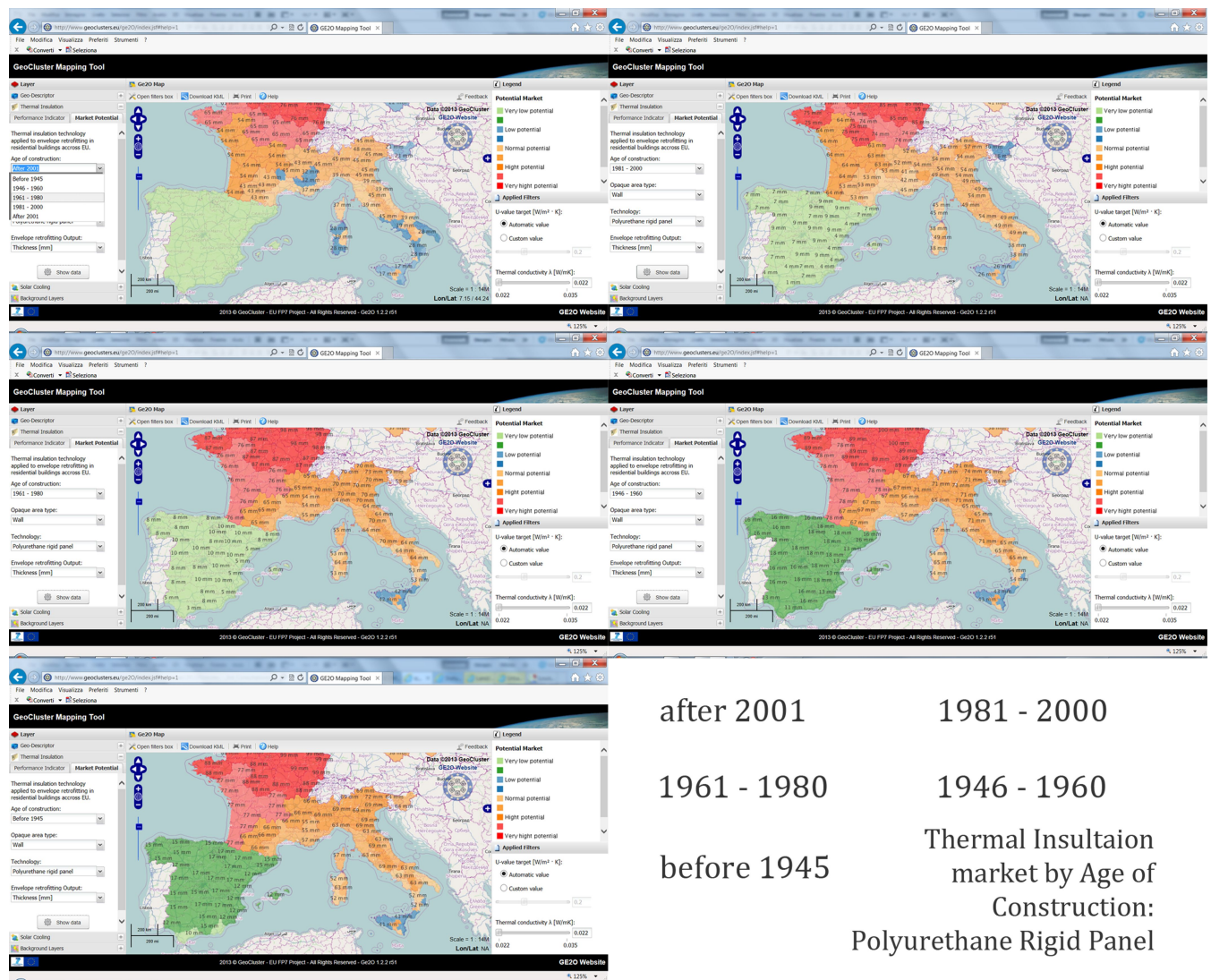

Figure 5. Market potential for Thermal Insulation Sheep Wool natural material: application to buildings of specific threshold categories, as classified by Eurostat and national statistic bodies.

this information into tools such as GE2O can benefit the overall market uptake in the field of EE in buildings.

\section{Conclusions}

It is widely acknowledged that $\mathrm{Gl}$ is increasingly becoming important for public users and professionals because it is useful to illustrate and enable analysis of phenomena occurring on territorial scales and because it can be integrated to simulate scenarios and forecast different phenomena. In this sense, Regional dimension and services specifically targeted to the priorities of Regions and needs of their citizens, can be very useful, also in view of a "macro-region" territorial concept. The "Macro Regional strategy" is an integrated framework used to address common challenges faced by a defined geographical area to strengthen the cooperation contributing to achievement of economic, social and territorial cohesion [24]. In the future, the further expansion of this concept will require tools to be able to support analysis of data and their correct integration for more informed decision making. In this sense, tools such as the GeoCluster Mapping Tool for mapping of Energy efficiency in Buildings can provide the structuring, clustering and integration of existing data on an EU level within the geospatial framework in order to address geo-cluster policies of Public Authorities and support professional related activities. This research highlights the potential integration of geo-portals and remote sensing information to provide inter-visibility of geospatial information for planners, private business developers and the public in the future. Geo-portals can bring added value to e-government management and to procedures regarding responding to interests of user communities [25]. The shift to community-based geo-portals will require a repository of meta-resources to be set up, as well as adopting technologies that enable the highest level of semantic interoperability within a framework to be able to integrate social and geographical dimensions. Many examples of geo-portals were built on a case by case approach. A more structured and coherent method is needed in order to make these tools competitive for governance and business development. The integration of web geo-portals with remote and on-site information could allow the expansion 
of further uses, thus contributing to enhanced knowledge and awareness of changes in territory, including climate, geophysical, ecomnoic, political and social impacts.

\section{Acknowledgments}

The research leading to the results of Geo-cluster Mapping Tool has received funding from the European Community's Seventh Framework Programme under grant agreement $n^{\circ} 285501$. The URL of the GeoMapping tool is http://www.GeoClusters.eu/ge2O/\#.

\section{References}

[1] Goodchild M.F., The use cases of digital earth, International Journal of Digital Earth, 2008, 1,1, 31-42

[2] Annoni A., Bernard L., Fullerton K., de Groof H., Kanellopoulos I., Millot M., et al., Towards a European spatial data infrastructure: The INSPIRE initiative. In: Proceedings of the 7th international global spatial data infrastructure conference, Bangalore, India, 2004

[3] Tait M.G., Implementing geoportals: applications of distributed GIS, Computers, Environment and Urban Systems, 2005, 29, 33-47

[4] Groot R., McLaughlin J. (Eds.), Geospatial data infrastructure: concepts, cases, and good practice. New York, Oxford University Press, 2000

[5] FGDC, The 1994 plan for the national spatial data infrastructure-building the foundation of an information based society. Washington: FGDC 1994

[6] Rhind R.W., Spatial Data Infrastructure. In: Smelser N.J., Paul B.B. (Eds), International encyclopedia of the social \& behavioral sciences, 2001, 14778-14785

[7] Maguire D.J., Longley P.A., The emergence of geoportals and their role in spatial data infrastructures, Computers, Environment and Urban Systems, 2005, 29, 3-14

[8] De Longueville B., Community-Based Geoportals: The Next Generation? - Concepts and Methods for the Geospatial Web 2.0, Computers Environment and Urban Systems, 2010, 34, 299-308

[9] FGDC, Geospatial one-stop: encouraging partnerships to enhance access to geospatial information, http://www.fgdc.gov/publications/documents/geninfo/gos.p

[10] Busby J. R., Kelly P., Australian spatial data infrastructures. In: The proceedings of the $7^{\text {th }}$ international global spatial data infrastructure conference, Bangalore, India, February 2-4, 2004, 10 pages, http://www.gsdidocs.org/gsdiconf/
GSDI-7/papers/NIjb.pdf

[11] Sivakumar R., Rao M., Dasgupta A.R., Perspectives of India national spatial data infrastructure - The Vision Ahead. In: The Proceedings of the 7th international global spatial data infrastructure conference, Bangalore, India, February 2-4, 2004, 18 pages. http://www.gsdidocs.org/gsdiconf/ GSDI-7/papers/NIskk.pdf

[12] Craglia M., Campagna M., Advanced Regional SDI in Europe: Comparative cost-benefit evaluation and impact assessment perspectives, The International Journal of SDI Research, 2010, 5, 145-167

[13] Cuca B., Brumana R., Scaioni M., Oreni D., Spatial Data Management of Temporal Map Series for Cultural and Environmental Heritage, International Journal of Spatial Data Infrastructure Research (IJSDIR), Selected Articles from INSPIRE 2010, 6, 95-127

[14] Dalla Costa S., Roccatello E., Rumor M., A CityGML 3D Geodatabase for builidngs' Energy Efficiency, Int. Arch. Photogramm. Remote Sens. Spatial Inf. Sci., 384/C21, 19-24, doi:10.5194/isprsarchives-XXXVIII-4C21-19-2011, 2011

[15] Cuca B., Sesana M.M., lannaccone G., Oreni D., Caccavelli D., Integration of the multi-scale heterogeneous data for the deployment of the concept of energy efficiency in buildings within an SDI framework. In: Proceedings of 13th Int. Conf. on Computational Science and Its Applications -ICCSA 2013 B. Murgante et al. (Eds.): ICCSA 2013, Part IV, LNCS 7974, pp. 358-374, 2013

[16] Kibria M.S., Zlatanova S., Itard L., Van Dorst M., GeoVEs as tools to communicate in urban projects: requirements for functionality and visualisation, In: Lee J., Zlatanova S. (Eds), 3D geo-information sciences, LNG\&C, Springer Verlag, 2009, 379-395. DOI: 10.1007/978-3-540-87395-2_24

[17] Oreni D., Brumana R., Cuca B., Towards a Methodology for 3D Content Models. The Reconstruction of Ancient Vaults for Maintenance and Structural Behaviour in the logic of BIM management. In: Guidi G., Addison A.C., Virtual Systems in the Information Society. NJ, USA: IEEE, Milan, Italy, 2 - 5 September 2012, 475-482

[18] Brumana R., Oreni D., Cuca B., Binda L., Condoleo P., Triggiani M., Strategy for integrated surveying techniques finalized to interpretive models in a byzantine church, Mesopotam, Albania, International Journal of Architectural Heritage, in press

[19] Brumana R., Prandi F., Use of 3D GIS to Model Urban environment. In: Volker Coors, Sisi Zlatanovaet al. Urban and Regional Data Management UDMS2007 Annual. LONDON: Taylor and Francis 
Group, Stuttgart, 2008, 223-230

[20] Hay G.J., Kyle C., Hemachandran B., Chen G., Rahman M.M., Fung T.S., Arvai J.L., Geospatial Technologies to Improve Urban Energy Efficiency. Remote Sens. 2011, 3, 1380-1405

[21] Weng Q., Thermal infrared remote sensing for urban climate and environmental studies: Methods, applications, and trends. ISPRS J. Photogramm. Remote Sens. 2009, 64, 335-344

[22] Voogt J.A., Oke T.R., Thermal remote sensing of urban climates. Remote Sens. Environ. 2003, 86, 370-384

[23] Towards an urban atlas: Assessment of spatial data on 25 European cities and urban areas, Environmental issue report No 30,
EEA (European Environment Agency), 2002. http://www . eea.europa.eu/publications / environmental_issue_report_2002_30, last access 10 March 2014

[24] Website of DG Regional Policy, http: //ec . europa . eu/regional_policy/index_en.cfm Last access 10 March 2014

[25] Song H.J., E-government: lessons learned and challenges ahead. In The 8th international seminar on GIS: envisioning cyber-geospace and spatially enabled e-government, November 20-21, Seoul, Korea, Korea Research Institute for Human Settlements, 2013, 1-13 